\title{
Geoinformation planning for location of solid municipal waste accumulation sites to ensure urban safety and environmental sustainability
}

\author{
Evgeny Ilyich Avrunev ${ }^{1}$, Alexey Viktorovich Dubrovsky ${ }^{1 *}$, Anatoly Viktorovich Ershov ${ }^{1}$, \\ Olesya Igorevna Malygina ${ }^{1}$, Andrey Gennadievich Sharikalov ${ }^{2}$ \\ ${ }^{1}$ Siberian State University of Geosystems and Technologies, Plakhotnogo Ul., 10, 630108 \\ Novosibirsk, Russia \\ ${ }^{2}$ Department of Energy, Housing and Utilities of the Novosibirsk Mayor's Office, Trudovaya, 1, \\ 630099 Novosibirsk, Russia
}

\begin{abstract}
The article describes results of research work on planning for location of solid municipal waste accumulation sites, as well as the creation a register of solid municipal waste accumulation permanent plots in Novosibirsk. The requirements for the site placement land plot, as well as the applicable process operations for picking the optimal site location are shown. Quantitative data on solid municipal waste accumulation sites in Novosibirsk and the geoinformation database structure are given. Conclusions on the importance of the work carried out for the ecological well-being of Novosibirsk, the creation of a comfortable and safe living environment for the population are made.
\end{abstract}

\section{Introduction}

In conformity with the Federal law No. 503-FZ dated December 31, 2017, amending the Federal Law on Production and Consumption Wastes and separate acts of the Russian Federation, local authorities of urban districts in the field of solid municipal waste management are obliged to define schemes of solid municipal waste accumulation places (sites) and to carry out maintenance of register of solid municipal waste accumulation places (sites). Since urban solid municipal waste (SMW) shall be collected at specially created places (sites) it is necessary to determine their location, including not only address marks, but also coordinates [1]. There were no works performed on the placement of solid municipal waste accumulation permanent plots (SCWAPP) on the territory occupied by free-standing residential buildings. In this regard, the Department of Energy, Housing and Utilities of the Novosibirsk in the period from 2019 to 2021 offered 2 grants to perform work on geoinformational planning for location of solid municipal waste accumulation sites. Research group of the Department of Cadastre and Territorial Planning of the Siberian State University of Geosystems and Technologies won the competition to carry out these works.

*Corresponding author: avd5@ssga.ru 
Designing of SCWAPP locations is an important task, since both total volume of SMW collected and exported from the territory of private sector and the environmental situation on the territory will depend on the choice of site optimal location [2-4]. In addition, optimal design of SCWAPP locations is aimed at prudent management of municipal district land resources. SCWAPP location choice is a complex multi-component task which requires use of geoinformation systems allowing for dimentional analysis and geomodeling.

\section{Materials and Method}

Location planning of sites for SCWAPP construction on private sector territory was performed in compliance with the SanPiN 2.1.7.3550-19 requirements [5]. All the requirements are systematized in order to determine the SCWAPP optimal location on the territory of settlements with minimization of ecological harm to the environment, as well as minimization of costs for SCW removal. The main requirements are:

- site location on municipal property plots;

- solid municipal waste collection site is to be located not closer than $20 \mathrm{~m}$ from the residential houses and not further than $100 \mathrm{~m}$;

- specialized transport access to the site is ensured;

- sites are located on the routes of diurnal migration of population;

- site selected for SCWAPP is not located in areas with special use conditions, established for engineering communications.

Digital address plan of Novosibirsk at a scale of 1:2,000 was used as the source digital map document for SCWAPP location geoinformation planning. This plan is included in the GIS Inventory database, the rightholder of which is Siberian State University of Geosystems and Technologies [6]. Remote sensing data (space images as well as orthophotos for the Novosibirsk part) and a raster topographic plan at a scale of 1:500 were used as additional information to make a decision on selection of SCWAPP meta-location. To create a digital plan of operating SCWAPP location, the data obtained by measuring coordinates of centers of the sites using GPS/GLONASS receivers was used.

MapInfo Pro v2019 geoinformation system was used as a tool to perform geoinformation planning. Automation of work with raster images, search for the necessary raster file and control of engineering communications transmission near the SCWAPP supposed site, was carried out with the use of its own software BatchTIFF [7].

\section{Results and Discussion}

When picking the SCWAPP location, number of residents, their density, routes of population diurnal migration, climatic and weather conditions of territory, terrain relief, ownership of land plots to a certain type of property (municipal), location of real estate and elements of engineering, transport, social infrastructure, existing spontaneously formed unauthorized landfills, Fig. 1.
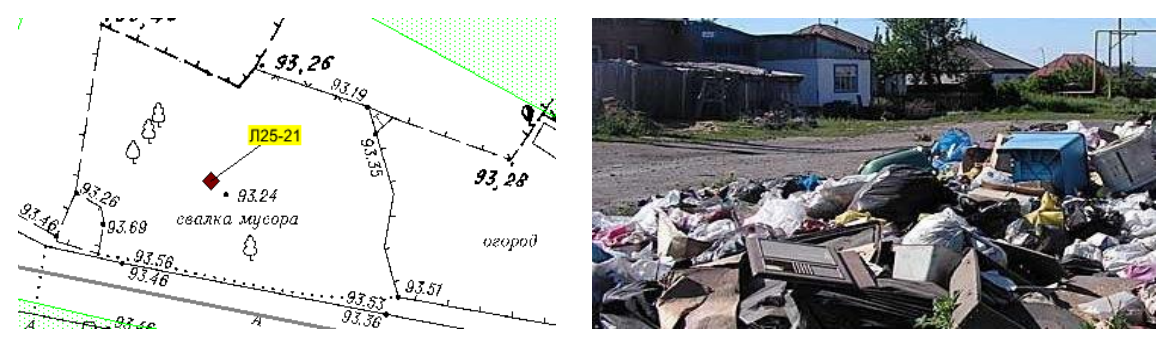

Fig. 1. Examples of unauthorized spontaneous landfills 
As a rule, spontaneous landfills occur on plots that are municipal property. These land plots do not have an owner as individual or a legal entity, the plots are not fenced and are littered with SMW. Spontaneous landfills pose a threat of land contamination and ingress of hazardous substances into groundwater, and then into water sources, such as bores, wells. It is possible to identify such violations on the basis of field surveys, including the use of unmanned aerial systems technology and remote sensing data $[8,9]$.

On the basis of address plan and made additional graphic constructions in the form of buffer zones of 20 meters indentation from residential houses and working radii of 100 meters relative to SMWAPP on lands of municipal property, location of 2,303 centers of land plots under the SMWAPP was projected. An analysis of movement routes of population to public transport stops was performed. In places where it is possible and does not contradict all the conditions of SMWAPP location, sites were designed as close as possible to the movement route of population. Diurnal migration of population along the routes to public transport stops is on average 5 times greater than the number of population movements along other routes of travel. Therefore a 250 meter buffer zone was built in relation to the public transport stops to identify the most demanded SMWAPP and recommendations were made to equip them with additional containers. Design scheme example of projected position of solid municipal waste accumulation sites, considering the scheme of diurnal migration of population, is shown in Fig. 2.
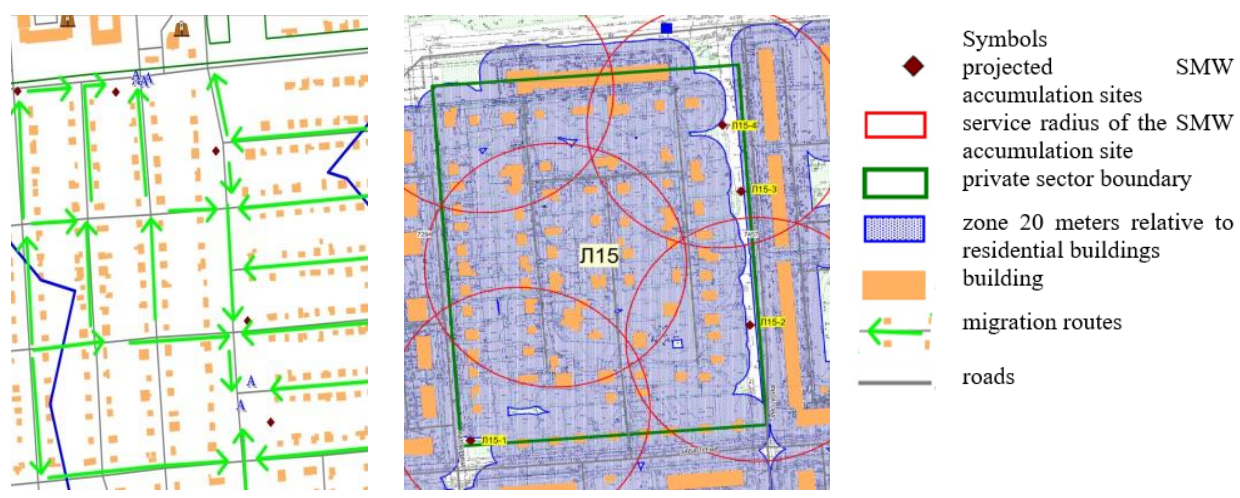

Fig. 2. Schematic diagram of SMWAPP design position

According to the results of geomodelling and geoinformation analysis, about 2,634 SMWAPPs are required for individual residential areas of Novosibirsk. In more than 300 cases, it is not possible to set exact coordinates for SMWAPP design to serve the nearby residential buildings, because the SanPiN requirements [5], Fig. 3. Therein, technical solution was to determine the design radius of service of SMWAPP residential buildings. This approach made it possible to determine the total need for SMWAPP.

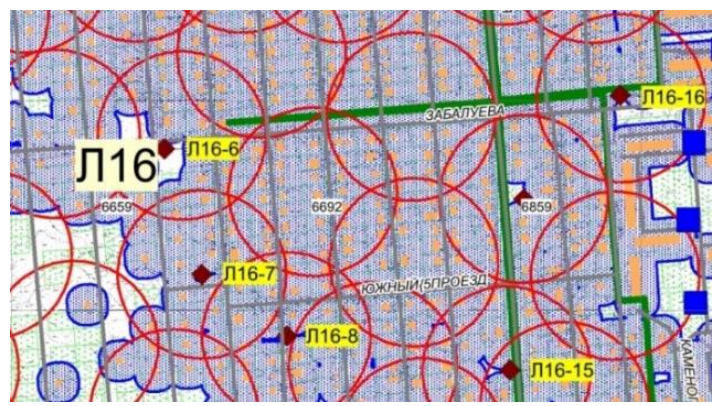

Fig. 3. Example of SMWAPP establishing impossibility 
Most cases of inability to design SMW site are related to the fact that residential buildings are close to each other and the minimum distance requirement of SMWAPP from residential buildings is not complied with. The second most common reason is the lack of access for specialized equipment to the SMWAPP land plot, which meets the necessary requirements in the distance from residential buildings. Locations of all the planned SMW accumulation sites were clarified by topographic plans of 1:500 scale in order to avoid their location in the protected zones of utilities. As a result of this work a catalog of coordinates of projected SMWAPP centers was compiled. Example of designing the SMW accumulation site optimal position is shown in Fig. 4.

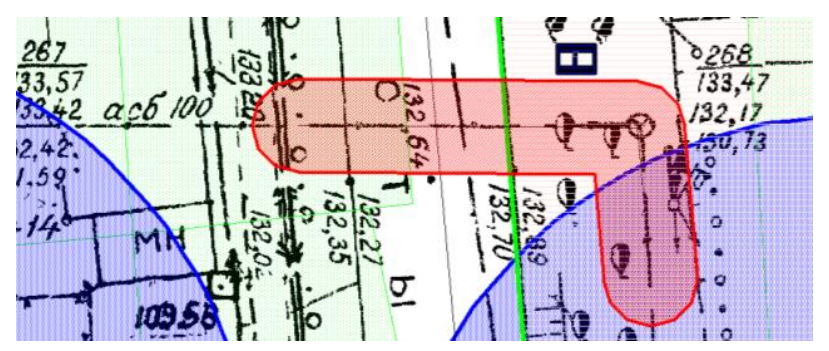

Fig. 4. Example of designing the SMWAPP optimal position

Existing in the city SMWAPP were mapped on a digital address plan. In total, there are 7,867 SMWAPPs in Novosibirsk. The work on clarification of their location and a geoinformation database formation was carried out. The following information was entered into the database that characterizes SMWAPP: site number, location area, address mark (house address to which the site belongs), site coverage type, site, name and address of service organization, number and type of containers (for example, draw-out), volume of containers, number and volume of bins (if any), characteristics of capital construction object that served by SMWAPP, availability of containers for waste sorting, type of the land plot ownership on which the SMWAPP is located.

\section{Conclusion}

1. Created SMWAPP geoinformation database allows to automate the process of waste removal and provide intelligent calculation of the optimal routes of specialized transport. Therein, the achieved effect is expressed in reduction of SMWAPP service time as well as in reduction of harmful emissions produced by specialized vehicles.

2. The collected and systematized information on SMWAPP is presented in a convenient and visual form, including a cartographic one, which significantly facilitates management processes and decision-making on sustainable development of Novosibirsk.

3. Performed geoinformation planning for location of solid municipal waste accumulation sites allows meeting the requirements for ensuring environmental safety in areas of individual residential development in Novosibirsk.

4. Identified places of unauthorized and spontaneous landfills are marked on digital address plan of the city. Relevant report was transferred to the Department of Energy, Housing and Utilities of Novosibirsk for their subsequent elimination and creation of equipped SMWAPP in their place.

5. The use of geoinformation design and geoinformation analysis software tools, as well as a set of hardware and equipment for collecting spatial data allows to automate process of designing and establishing the SMWAPP optimal location. 
6. According to the results of geoinformational analysis the position of $87 \%$ of SMWAPP location places was projected, which meet the requirements of SanPiN, and also consider the ways of population diurnal migration.

\section{Acknowledgements}

Team of authors acknowledges the Mayor's Office of Novosibirsk, as well as the management of the Department of Industry, Innovation and Entrepreneurship of the Mayor's Office of Novosibirsk for providing grant support for research work on geoinformation planning of solid municipal waste accumulation sites to ensure the safety and environmental sustainability in Novosibirsk. The authors also express their gratitude to the Administration of the Siberian State University of Geosystems and Technologies and personally to the Rector of the University A. P. Karpik for financial, organizational, scientific and technical support of research aimed at ensuring environmental safety and prudent management of land resources of Novosibirsk in the interests of present-day society and future generations.

\section{References}

1. Amending the Federal Law on Production and Consumption Wastes and separate acts of the Russian Federation. Federal law dated December 31, 2017, 503-FZ, 35 (2017)

2. A.P. Karpik, A.G. Osipov, P.P. Murzintsev, Territory Management in Geoinformation Discourse: Monograph, 280 (2010)

3. On Protection of Environment. Federal Law of the Russian Federation No. 7-FZ dated January 10, 2002. - Rossiyskaya Gazeta dated January 12, 2002, 2874 (2002)

4. On Approval of Solid Municipal Waste Accumulation (including separate accumulation) Procedure in the Novosibirsk Region (as amended on September 21, 2020). Government Decree of the Novosibirsk Region dated May 11, 2017, 176-p, 22 (2020)

5. On Approval of Sanitary and Epidemiological Rules and Norms SanPiN 2.1.7.3550-19 "Sanitary and Epidemiological Requirements for the Maintenance of Municipal Formations". Russia's Chief Public Health Officer Decree dated December 5, 2019, 20, 12 (2019)

6. A.V. Ershov, V.N. Nikitin, A.V. Dubrovsky, O.I. Malygina, A.V. Ivanova, Certificate of GIS Inventory database registration, No. 2019621245 dated July 11, 2019 (2019)

7. A.V. Ershov, A.V. Dubrovsky, A.A. Kolesnikov, N.A. Belyaeva, Certificate of BatchTIFF software registration, No. 2020663917 dated November 05, 2020 (2020)

8. G.A. Ustavich, A.V. Dubrovsky, Ya.G. Poshivaylo, A.O. Grekova, O.I. Malygina, Vestnik SSUGT, 24 (3), 203 (2019)

9. B.I. Kochurov, A.Yu. Karandeev, Interkarto-2018, 24, 310 (2018) 